\title{
Automatic Surveillance and Control System Framework-DPS-KA-AT for Alleviating Disruptions of Social Media in Higher Learning Institutions
}

\author{
Kasaye Asres' ${ }^{1}$ Amin Tuni Gure1, Durga Prasad Sharma ${ }^{2 *}$ \\ ${ }^{1}$ Arba Minch University, Arba Minch, Ethiopia \\ ${ }^{2}$ AMUIT MOEFDRE under UNDP \& Research Adviser, MAISM-RTU, Kota, India \\ Email: asres21turuneh@gmail.com, amint134@yahoo.com, ^dp.shiv08@gmail.com
}

How to cite this paper: Asres, K., Gure, A.T. and Sharma, D.P. (2020) Automatic Surveillance and Control System Framework-DPS-KA-AT for Alleviating Disruptions of Social Media in Higher Learning Institutions. Journal of Computer and Communications, 8, 1-15.

https://doi.org/10.4236/jcc.2020.81001

Received: November 26, 2019

Accepted: December 28, 2019

Published: December 31, 2019

Copyright $\odot 2020$ by author(s) and Scientific Research Publishing Inc. This work is licensed under the Creative Commons Attribution International License (CC BY 4.0).

http://creativecommons.org/licenses/by/4.0/

\begin{abstract}
The worldwide change and transformations are taking place in socio-techno cultures. In the epicenter of all these Information and Communication Technologies (ICTs), the Internet is the backbone and paving salient communications and computations Medias like the emergence of social networking sites (SNSs). These SNSs are facilitating globalized entertainment, socialization, communications, and information sharing over hand-held electronic gazettes/mobiles like Facebook, Twitter, Instagram, Skype, and WhatsApp etc. The positive side of these SNSs is making the world a social village but apart from these positive aspects, there is another trait of multifold adversities/disruptions or negative effects which still have not been exposed and drawn attention. The remedial action for such adversities is needed to be designed and developed. The all age groups and genders are typically involved and resulting in wastage of time, money and peace of minds. The adverse effects of social media users in a Higher Learning Institutions are getting worse day-by-day. The prime aim of this research study is to design an automatic Surveillance System Framework for alleviation of the social media disruptions in these institutions. This framework aims to design and develop a surveillance system and access control guidelines for judiciously alleviating the misuse of social media. The study used MS form, Protopie, adobe XD and InVision for data collection, framework design and prototype development respectively. This research is an attempt to apply an explanatory and applied research design science approach using survey, interviews and technical observations-based primary data analytics. The study concluded with a cloud-based automatic surveillance, auto alerts and control system framework (DPS-KA-AT)
\end{abstract}


and functionally validated by a system framework prototype. In the survey and interview, the $66 \%$ respondents' response was "YES", while $34 \%$ "NO" when enquired for the need assessment of the automatic surveillance and control system towards alleviation of the social media adversities or disruptions. This percentage indicates that the highest number of respondent or the highest number of higher learning institutions communities need an urgent automatic monitoring, surveillance and control system towards alleviation of such adversities/disruptions. The study concluded with a remark "a concrete and Automatic Surveillance and Control System Framework can be a great instrumental for minimizing the adversities of social media in higher learning institutions".

\section{Keywords}

Surveillance, Social Media, Addiction, Adversities, Framework, Cloud, Disruptions

\section{Introduction}

The entire world and the people are dramatically changing their work, communication and social culture with respect to changes in the time and innovation. Today social Medias have been playing an energetic and abundant role with high dynamism in our day to day life. For instance, education, health, manufacturing, agriculture and business fields are extensively using social Medias for transforming their Computations, Communications and Collaborations towards new paradigms of smarter generation with multidimensional excellence through different kinds of electronic devices such as: laptop, desktop, computer, palmtop, tablet and smartphone.

Cloud computing technologies are providing evolutionary tools for the end to end transformations of our communication cultures. The studies [1] [2] [3] elaborate the salient features and strategies that how cloud has become a robust platform for re-engineering of communication and social Media's emergence.

Social media is the term often used to refer to new forms of media that involve interactive participation. The development of media is divided into two different ages. i.e. broadcast and interactive age. In the broadcast age, medias were almost exclusively centralized. Such as a Radio or Television station, Newspaper Company, or a Movie production studio which distribute messages to many people. While in the interactive age digital and mobile technologies are used. It became cooler for individuals before with large scale. In the interactive age, individual persons were unable to speak to so many people with instant feedback but today it's possible in an instant of time. The low cost and accessibility of new technology also allowed more options for media consumption than ever before. At the core of this ongoing revolution is social media. Social media has two common characteristics to define: First, social media allows some forms of participation [4].

Social media is never completely passive, even if sometimes social networking sites such as Facebook may allow passive viewing of what others are posting. 
Usually, at simple minimum, a profile must be created that allows for the beginning of the potential for interaction. That quality in and of itself sets social media apart from traditional media where personal profiles are not the norm. Second, and in line with their participatory nature, social media involve interaction. This interaction can be with established friends, family, or acquaintances or with new people who share common interests or even a common acquaintance circle [5].

\section{Problem under Investigation with Goal of the Research}

Human beings have a long life experience of communication and information transferring in this world to make the life simple and comfortable. The way of communication is changed from generation to generation as there is a change in innovation. These innovations lead to emergence of technologies. But it's observed that these Medias are becoming an addictive factor for human generations. University communities in general and Ethiopia in specific are also required to expose to the addiction and misuse of social Medias. Social media addiction is also called as process addiction, which has negative effects on students and government employees in their time and work management. Family relationship with their children, husband-to-wife, and neighbor-to-neighbor are also getting affected. Disturbance in social life and political instabilities are also in the heart of the social Medias. All across the world, it has been observed by research studies [6] [7] that the social Medias and systems are trying to make human generation addicted. As a slow poison human generation is gradually becoming the "slave" of technology rather than "savvy". As final game of human generation seems that it is totally surrendered and became the slave of the social Medias or Technology. This adverse effect can be seen every day and everywhere among every age group people from poor to rich, male to female, east to west, north to south, top to bottom, bottom to top and educated to uneducated.

The prime goal of this research paper is to design an Automatic Surveillance and Control System Framework with a Prototype Design for alleviating Adversities and Disruptions of Social Media in Higher Educational Institutions in general and Ethiopia higher learning institutions as specific case study and analysis.

\section{Review of Related Research Literature}

In order to understand the contribution of different researchers in the world; this study reviewed several research papers, Journal papers and thesis documents. The summary of reviewed papers is summarized in Table 1.

\section{Summary with Research-Ability Remarks/Knowledge-Gap}

Researcher surveyed the existing related research works in the problem identified area. A few research papers were found which are only focused to identify whether social Medias have effect on human generation or not in specific developed countries mainly in academic context. Most of the papers reviewed in this study did not cover the addictive nature of social Medias [8] [9] [10]. And the most of the studies failed to suggest/design or model to reduce the addictiveness 
Table 1. Summary of related research works review with critical remarks.

\begin{tabular}{|c|c|c|c|c|}
\hline No & Title of the Research & Author, Year & Significant Contributions & $\begin{array}{l}\text { Critical Remarks with } \\
\text { researchability gapes }\end{array}$ \\
\hline 1 & $\begin{array}{l}\text { A Quantitative Research } \\
\text { on the Level of Social } \\
\text { Media Addiction among } \\
\text { Young People in Turkey }\end{array}$ & $\begin{array}{l}\text { Ali Murat Kirik, } \\
\text { Ahmet Arslan, } \\
\text { Ahmet Çetinkaya, } \\
\text { Mehmet Gül1, } \\
\text { September 2015 }\end{array}$ & $\begin{array}{l}\text { Researcher aims to determine the } \\
\text { level of social media addiction in } \\
\text { young people in Turkey, and to } \\
\text { make suggestions on the prevention } \\
\text { of the addiction while stating the } \\
\text { current work carried out on the } \\
\text { subject in Turkey. }\end{array}$ & $\begin{array}{l}\text { The findings of this research paper } \\
\text { are relevant and related to the proposed } \\
\text { study. It assesses the addiction of social } \\
\text { media among young people; but still } \\
\text { there is no contribution to control } \\
\text { among close user group. }\end{array}$ \\
\hline 2 & $\begin{array}{l}\text { Cyber psychology, Behavior } \\
\text { And Social Networking } \\
\text { (Online Social Networking } \\
\text { and Mental Health) }\end{array}$ & Dr. Igor V. Pantic, 2014 & $\begin{array}{l}\text { This concise review paper focuses } \\
\text { on the recent findings regarding the } \\
\text { suggested connection between SNS } \\
\text { and mental health issues such as } \\
\text { depressive symptoms, changes in } \\
\text { self-esteem, and Internet addiction. }\end{array}$ & $\begin{array}{l}\text { In this research Researcher aims only } \\
\text { to conduct a concise review focuses } \\
\text { on the recent findings regarding the } \\
\text { suggested connection between SNS and } \\
\text { mental health issues such as depressive } \\
\text { symptoms, changes in self-esteem, and } \\
\text { Internet addiction, rather than finding } \\
\text { some framework or guideline to } \\
\text { prevent addiction and abuse. }\end{array}$ \\
\hline 3 & $\begin{array}{c}\text { Prevalence of Social } \\
\text { Networks Addiction } \\
\text { among Ethiopian Youths }\end{array}$ & $\begin{array}{l}\text { Shafaat Hussain1, and } \\
\text { Mohd. Arasad Volume } 4 \\
\text { Issue 3, March } 2015\end{array}$ & $\begin{array}{l}\text { This study explores how far the } \\
\text { Ethiopian youths are addicted to } \\
\text { social networks. The objective of } \\
\text { this research is to analyze the age } \\
\text { and gender dynamics of youths } \\
\text { regarding social networks addiction. } \\
\text { In Addition There is a greater } \\
\text { possibility that some innocent } \\
\text { youths may engage in the unlawful } \\
\text { communications, unintentionally } \\
\text { which may put them into troubles }\end{array}$ & $\begin{array}{l}\text { In this research paper scope is } \\
\text { somewhat close to the current study } \\
\text { since it is in Ethiopia; but again } \\
\text { there is lack of proposing the } \\
\text { framework to reduce the addiction } \\
\text { nature of social media. }\end{array}$ \\
\hline 4 & $\begin{array}{c}\text { Social Media Network } \\
\text { Participation and Academic } \\
\text { Performance In Senior } \\
\text { High Schools in Ghana }\end{array}$ & Mingle \& Adams, 2015. & $\begin{array}{l}\text { The study revealed that majority } \\
\text { of respondents used WhatsApp and } \\
\text { Facebook for making friends and } \\
\text { chatting. In addition, the majority } \\
\text { of respondents experienced negative } \\
\text { effects such as poor grammar and } \\
\text { spelling, late submission of } \\
\text { assignments, less study time and } \\
\text { poor academic performance due } \\
\text { to the heavy participation on } \\
\text { social media networks. }\end{array}$ & $\begin{array}{l}\text { This research paper is focused on how } \\
\text { students networked and participated } \\
\text { on social media networks, time invested } \\
\text { by students on social networks, the } \\
\text { effects of social media on students' } \\
\text { grammar and spelling as well as the } \\
\text { effects of social network participation } \\
\text { on the student's academic performance } \\
\text { But there is no any addressed framework } \\
\text { for controlling such adversities. }\end{array}$ \\
\hline
\end{tabular}

of the social Medias among close user group [11] [12] [13]. This proposed study is an effort to investigate the factor-based adverse effect of this social Medias and other salient technologies involved in developing countries and then develops a framework for real-time surveillance and control over close user groups for reducing the disruption and adverse effects. Upon strong analysis of salient literature from various offline/online resources/media, it has been observed that there is a crystal clear research gap between the solutions have and the solution have not in the existing research literature. This justifies the strong need for conducting research and therefore this research study is worth doing. 


\section{Research Design and Methodology}

\subsection{Research Design}

The study uses Survey based Explanatory and Applied research in which a Framework is developed with functional Prototype to implement, validate and conduct the acceptance test of the research outcomes. The study starts upon identification and analysis of the utilization of social networking sites or social Medias in everyday activities. Also, the study covers only the university academic community stakeholders for academic tasks.

\subsection{Research Approach}

Collecting in depth technical facts about the current situation of social media utilization the motivation is to use qualitative and quantitative techniques. It provides insights into the setting and answering the reasons of the problem. In this research, the study has selected qualitative and quantitative methods for gathering the most important and relevant facts from the respondents who are target population and competent stakeholders to give detailed inputs and answers related to the research problem domain. This study used a mixed approach (i.e. both qualitative and quantitative) because of that the data collected is both in words and numbers; for data collection and analysis. The research methodology incorporates the statistical analysis of the data collected.

\subsection{Data Collection Procedure}

Figure 1 describes the data collection procedure in which the primary and secondary data are collected using survey, interview and observation with well-structured questionnaire and checklist and summarized for understanding the cause effect relationships of social media.

\subsection{Sampling Method}

In this study, Purposive sampling which represents a group of different nonprobability sampling techniques is used. Also known as judgmental, selective or subjective sampling, purposive sampling relies on the judgment of the researcher when it comes to selecting the units (e.g., people, cases/organizations, events, pieces of data) that are to be studied [14].

Based on this, the sample size for this research study was eighty-eight (88) which depends on different conditions and criteria's set by researcher for selecting respondents for Open-ended interview and Online Survey. Here the research study is more over scientifically applied and constructive and therefore eighty-eight (88) sample size is sufficiently representative for generalization.

\subsection{Data Analysis}

As the primary data is analyzed similar concept and result is observed under the several secondary data sources. The secondary data sources were also investigated and analyzed in this study. Several research documents from salient 


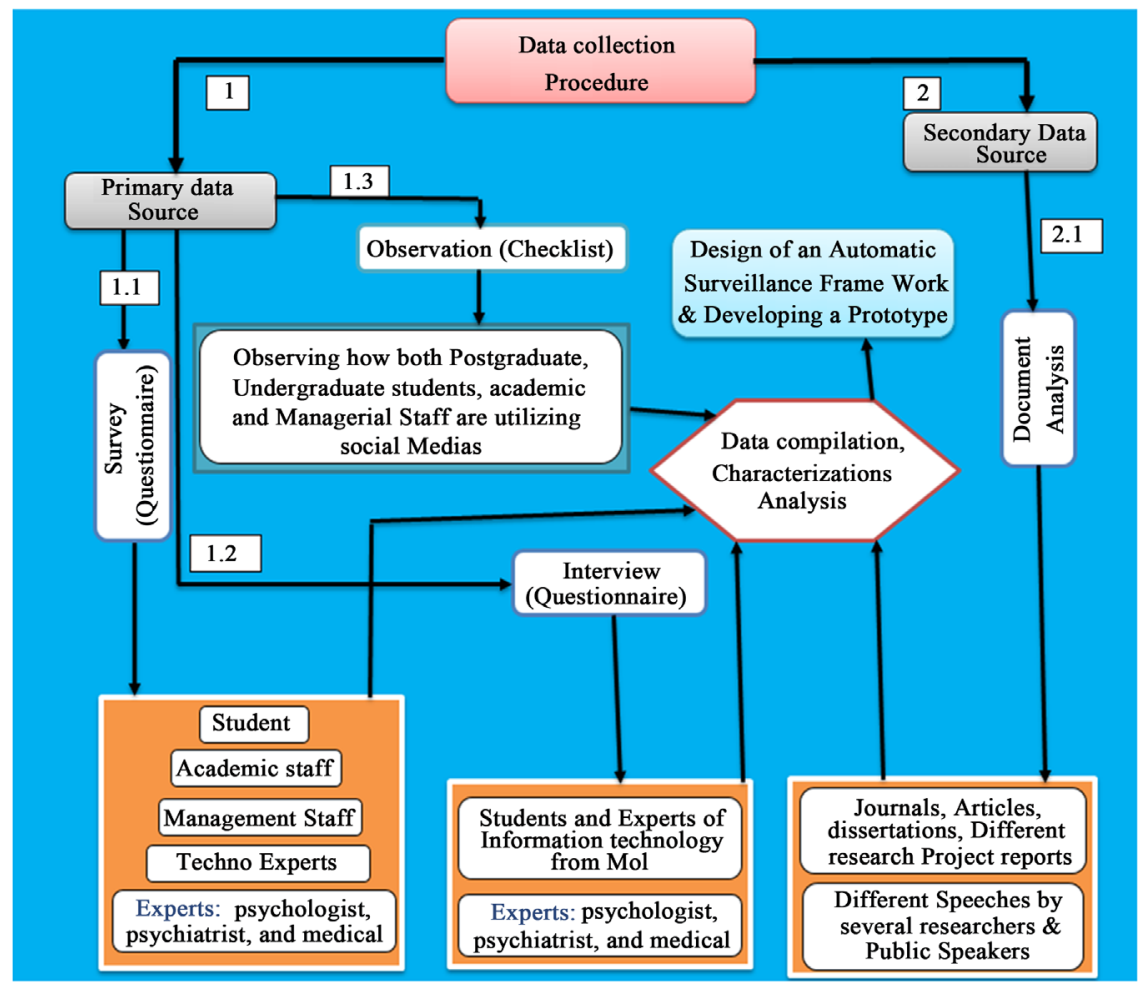

Figure 1. Data collection procedure.

sources such as: journals, articles, dissertation, related thesis, different research project reports those are conducted prior to this research were studied and analyzed. From other domains such as psychology, psychiatry, communication, health informatics, sport and behavioral science; while in the same domain or in technology: cloud-related technology, several framework design strategies, both prototype and application design or developments and mobile radiation control mechanisms related work, mobile tower installation works and family internet control apps with their documents are used as reviewed under the related work literature reviews. So that the analyzed data from all source reveals that there is a need for designing automatic surveillance and control system framework over cloud with prototype demonstration. The data is mainly used as an input for the framework design.

\subsection{Data Analysis and Discussion}

1) Have you ever violated command for using social networking sites when parents or teachers have asked you not to do?

This research survey question was about violating or not violating the families command or teachers. Hence the greater percentage as mentioned in Figure 2 (62\%) of the respondents responded "NO" while 38\% respondents responded "YES"; which clearly indicates that the code of conducts are seriously under threat and needs for alternative measures to control and alleviate.

2) Do you prefer to interact with people on social networking sites rather than face to face? 


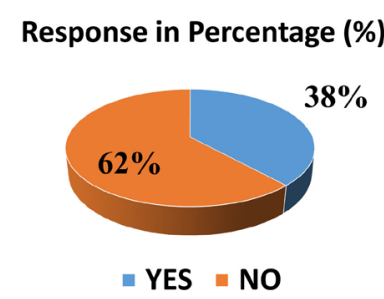

Figure 2. Violation of the code of conduct command for using SNS.

This question revealed an alarming state of threat where $46 \%$ respondents response was "YES" and 54\% response was "NO". This clearly indicates that majority of the university community i.e. $54 \%$ are not preferring SNS to interact with people and presented in Figure 3.

3) Did you get warning/command on how much time do you spend on social networking sites?

This question was confined to a warning state in which $36 \%$ respondents response was "YES" and 64\% response was "NO", which clearly indicates that there is lack of transparency among the university communities about how much time they are spending on several SNSs rather than core profession like academic and research. This indicator alarms the nature of SNS usage and puts forward (indicates) an arrow towards addiction or adversities. This state is motivating factor to develop control mechanisms through real time surveillance for judiciously to alleviation of SNS addiction among the university communities. Figure 4 presents the summarized percentage.

4) Have you ever got frustrated when the social networking site goes down or is unavailable?

This question covers the responses about psychoanalysis. Here the $61 \%$ response of the respondents was "YES" and 39\% was "NO". This once again clearly indicated that a large number of members of the university communities i.e. $61 \%$ got frustrated while occasionally SNS goes down or not working. This is one of an indication about social media and internet addiction. This phenomenon state once again indicates that there is a strong need of real-time surveillance and control mechanisms so as to target problem can be resolved to achieve the central goal of this research. Figure 5 presents the summarized response percentage of respondents.

5) What is your major aim to use the social media site?

From the selected sample $23.17 \%$ respondents responded that they use social media for reading news updates, $21.59 \%$ responded that they use for keeping them in touch with their friends, $12.38 \%$ responded to have the meeting with new friends, $10.79 \%$ responded for religious affairs, $8.89 \%$ for employment, 7.94\% for inspiration, $6.98 \%$ for political debate and discussion, $5.71 \%$ for browsing undetermined reading or watching stuff for passing the time and the $2.54 \%$ responded that they use for business affairs like buying and selling products and services. In addition to it, the researcher's observation also verified the responses in align with and indicates that the first three responses (reading news 


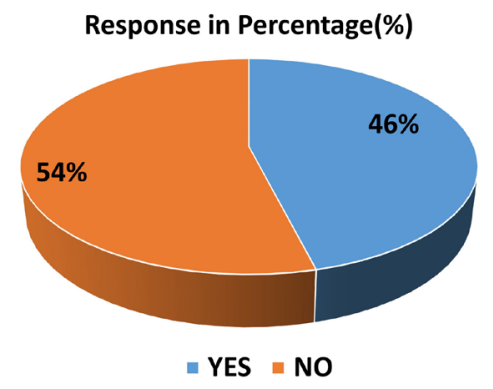

Figure 3. Do you prefer to interact with people on SNS rather than face to face.

Response in Percentage (\%)

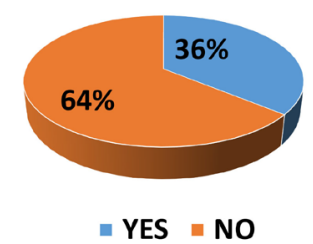

Figure 4. Warning on how much time spend on SNS.

Response in Percentage (\%)

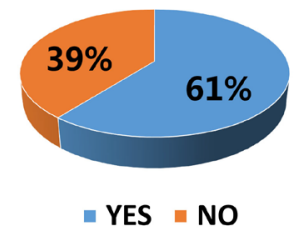

Figure 5. Have you ever got frustrated when the social networking site goes down or is unavailable?

updates, keeping in touch with friends and to meet new friends) are not considered as productive tasks on several SNS and considered to be addicted with SNS/social media. This phenomenon state also indicates that there is a strong need of the real-time surveillance and control mechanism to balance the productive and non-produce usage of the SNSs. The bar chart Figure 6 presents the summarized response percentage.

6) Where do you usually have the access to social media? (Work place, home, coffee place or other)?

This question was raised to verify the place of access to social media for checking the relationship between their business and personal affairs. From the selected sample size the $36 \%$ of the respondents' response was free WIFI, $30 \%$ uses private data anywhere, $22 \%$ uses education lab at their academic institutions and the rests $12 \%$ employees accepted that they use in their working offices. This indicates that university communities are involved in the violation of the code of conduct of the universities and indulged into illegal usage/access of several SNS/ social Medias everywhere inside the work place campuses. It irradiates the users' addiction possibilities of SNSs. Again, this is also an indication of worth 


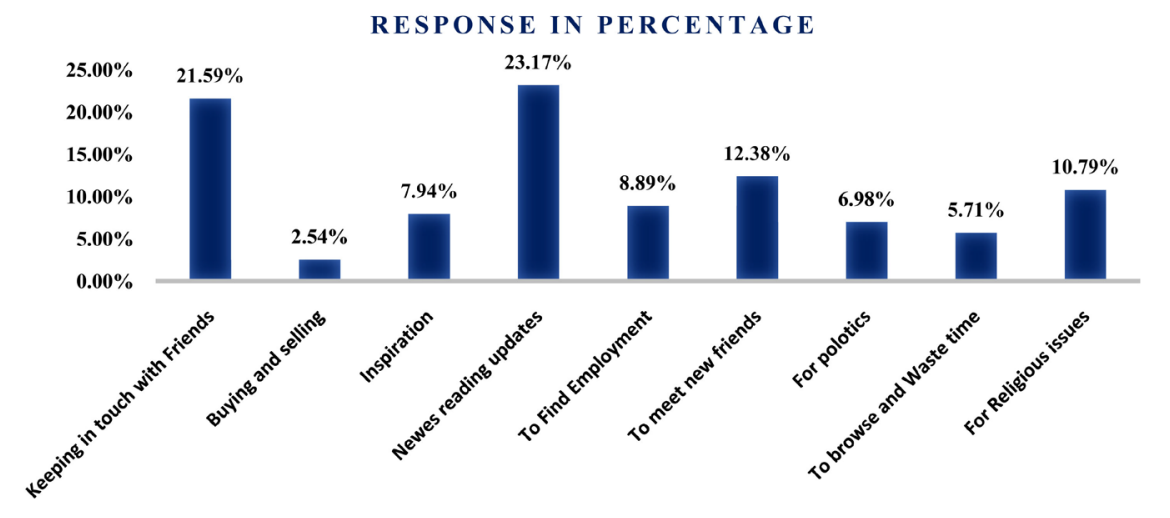

Figure 6. What do you use social media for?

researchability. Figure 7 presents the summarized response percentage of respondents.

7) How often do you find yourself saying "just a few more minutes" when using social media?

From the survey $4.55 \%$ respondents responded never, $6.82 \%$ very rarely, $10.23 \%$ rarely, and the largest percentage of respondents: which represents the largest number of university communities $(34.09 \%, 26.14 \%$, and $18.18 \%)$ response was sometimes, often and very often respectively. It is one of the clear indication of the addiction. Figure 8 presents the summarized response percentage of respondents.

8) How often do you feel stressed, disconnected, or paranoid when you are unable to access social media sites?

In this survey question, $19.54 \%$ of the respondents' response was never, $5.75 \%$ very rarely, $20.69 \%$ rarely, and the largest percentage of respondents: which represents the maximum number of university communities $(28.73 \%, 20.69 \%$, and $5.74 \%$ ) were sometimes, often and very often respectively. This result clearly indicates that the university communities have been feeling stressed out, disconnected, or paranoid when they are unable to access social media sites. This is again another indicator for revealing the threat of addiction of the SNSs. It makes the research work significantly important and provides a strong insight for the findings. The bar chart Figure 9 presents the summarized response percentage of respondents.

9) Do you feel that there is a strong and urgent need of a monitoring, surveillance and control system for alleviating the adversities/disruptions?

Hence from the survey the 66\% respondents response was "YES", while $34 \%$ "NO". This percentage indicates that the highest number of respondent or the highest number of higher learning institutions communities need an urgent automatic monitoring, surveillance and control system towards alleviation of such adversities/disruptions. Based on these investigations and findings this research study provides a solution for alleviation of such disruptions, which is a significant contribution of this research work. Figure 10 presents the summarized response percentage of respondents. 


\section{Response in percentage(\%)}

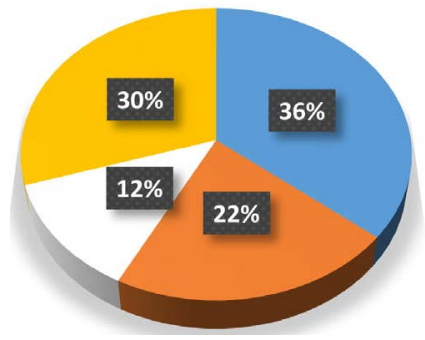

- Free WIFI

Education Labs

Employee Offices

Private Data Anywhere

Figure 7. Where do you usually have the access to social media? (Work place, home, coffee place or other)?

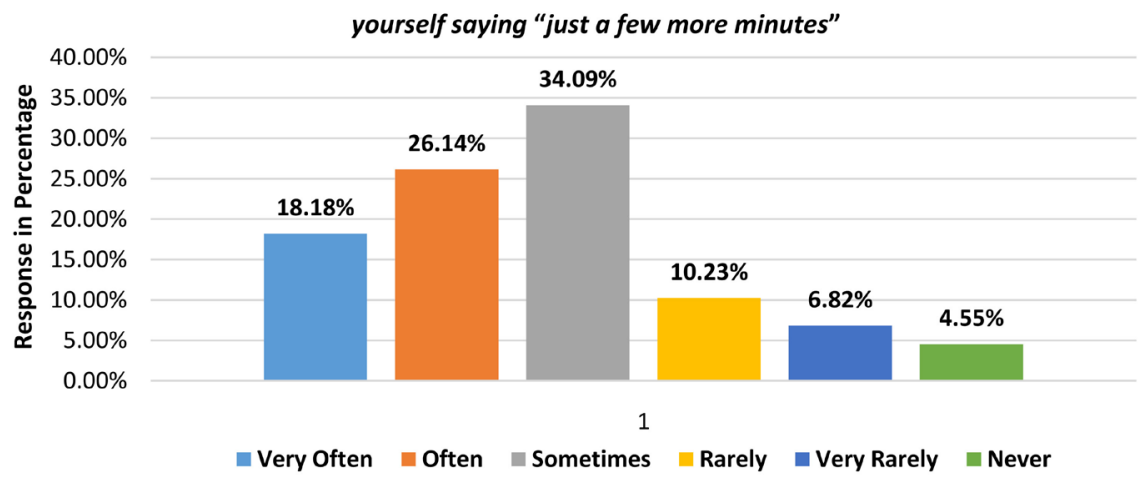

Figure 8. How often do you find yourself saying "just a few more minutes" when using SNS.

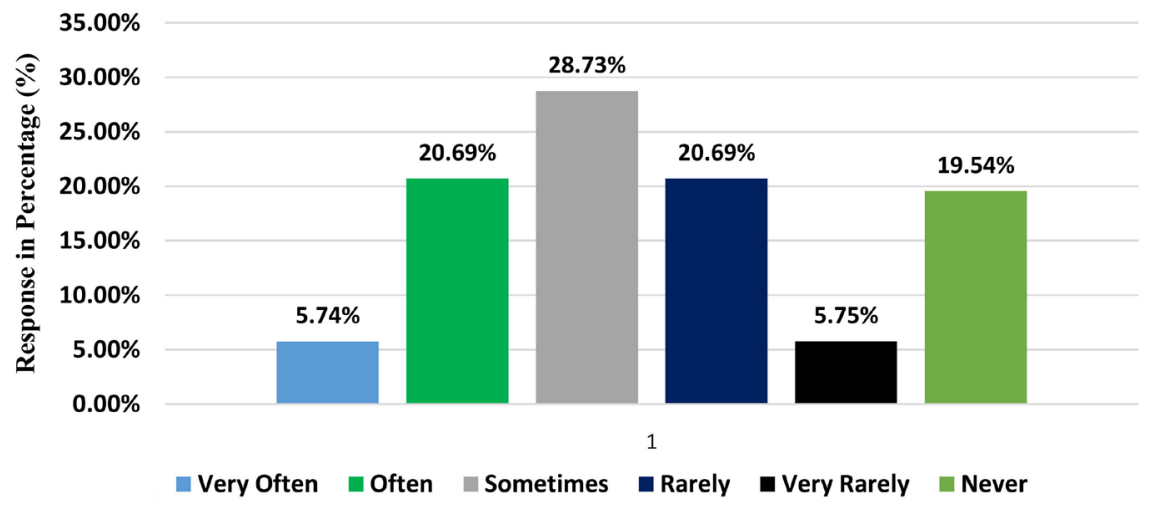

Figure 9. How often do you feel stressed, disconnected, or paranoid when you are unable to access social media sites?

\section{Response in percentage( \%)}

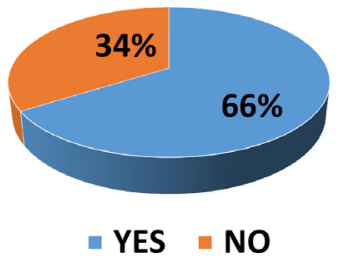

Figure 10. Do you feel that there is a strong and urgent need of a monitoring, surveillance and control system for alleviating the adversities/disruptions? 


\section{Designing an Automatic Surveillance and Control System Framework over Cloud Platform}

Figure 11 presents the general framework over cloud. It is designed by combination of different set of operations and services expected from the framework to be delivered at each of the three layers. The designed system framework over the cloud computing is clustered into three layers (SaaS, PaaS and IaaS) that is Upper/pre-request layer, middle/ transaction layer, and bottom/ application ending layer.

\subsection{Upper/Pre-Request Layer (SaaS)}

This pre-request layer is called as upper layer, because it is located at the top layer of the whole framework of the proposed system and it is the first mandatory layer to proceed for the next layer's functions/services. This pre-request layer consists of different functions like: loading function, signup function and login function.

Loading function: used to load the apps for the first time to use on a device. The loading of app takes place either offline or online.

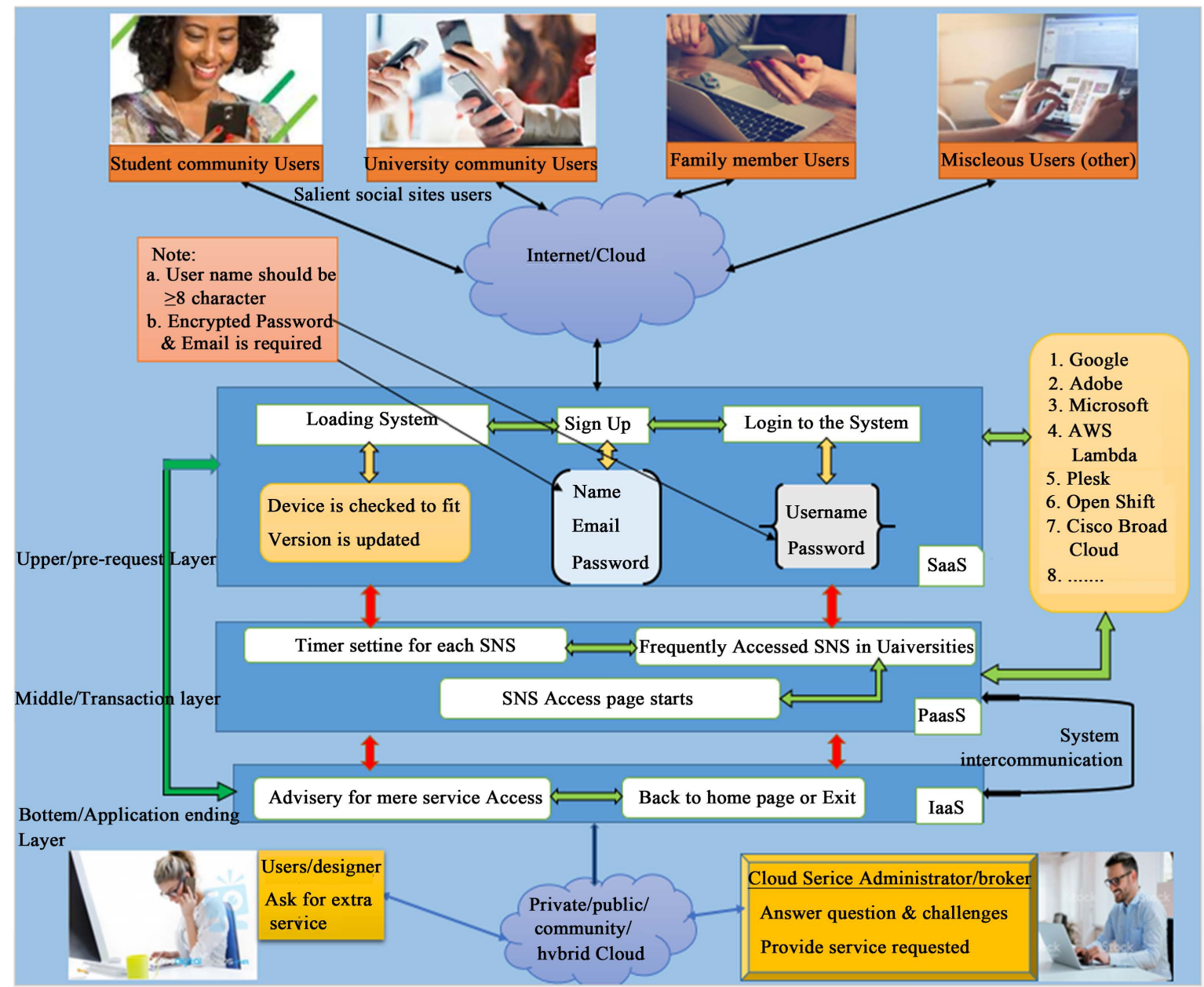

Figure 11. The automatic surveillance and control system framework over the cloud. 
Signup function: It is a function which is used to create an account for the system usage using name, email and password.

Login function: used to login to have access and get service of the proposed framework when transformed into a fully functional system using the previous signup attributes (username and password). Generally this upper layer proposed to use cloud service delivery mode of software as a service/SaaS.

\subsection{Middle/Transaction Layer (PaaS)}

Transaction layer is a layer after the upper layer. It consists of three functional page i.e. Timer setting for each SNS, frequently accessed SNS in universities and SNS access page of starts.

Timer setting for each SNS function: It is used in the proposed framework to handle time budgeting for all SNS, over any electronic devices for university communities. It allows users to jump for the next SNS access allow functions.

Frequently accessed SNS in University: This access SNS allows user to have an access for the top utilized SNS in Ethiopian Universities. It is designed to manage the service flow between timer setting and SNS access system function. It also controls the time set for the access on the top function level.

SNS access prototype page start. It is proposed to hold the frequently and predominantly accessed social Medias and allows the user to start an access according to the set time for them. Totally this middle layer is central parts of the proposed framework and platform as a service/PaaS cloud service delivery mode.

\subsection{Bottom/Ending Layer (IAAS)}

It is the final layer of this automatic surveillance and control system framework. It is designed to allow users of SNS to intercommunicate with the middle layer and also go back to the upper layer either to start another process or to exit. This application ending layer has two functions i.e. info \& advice and back or exit function. Description for each are as follows:

Info \& advice function: is a function designed to give updated information like: how to use social media in a balanced way, mechanism to be free from social media addiction, symptoms for social media/ internet addiction are posted and displayed for users to have an informed social media users/customers in Ethiopian universities.

Back or Exit function: is a function of prototype designed within this layer to allow user to return back to the main/upper and middle layer of this proposed automatic surveillance control system framework. At the same time it also allows the user to exit from the framework service and access.

Generally, this button/application ending layer of the proposed framework is called as infrastructure as a service of cloud service delivery mode. At all the summarized overview and description of this proposed automatic surveillance and control system framework is elaborated under prototype design and descriptions. 


\subsection{System Designer}

This framework also keeps the space for future designers or developers by availing cloud-based services, tools and techniques. In this section, the designer may specify the cloud deployment model based on the requirements of the business communication along with the surveillance and control. In addition to it, the developers also can think and decide the deployment strategies based on the requirements of the system set by the designer for the cloud services. Here the space for decision is open for both the designers and developers to avail the deployment model from private, public, and community or hybrid clouds.

\subsection{System Administrator/Broker}

This component of the framework facilitates and helps designers to select the most viable services based on the salient criteria's and suitability assessments. The best fit model and the designing or developing tools, techniques and infrastructure are provided with help/support of Cloud Service Provider (CSP) Admin or third party Broker.

\section{Prototype Design}

In this section, researcher presents a prototype of the proposed system framework. Here the desired prototype, which is designed and validated using experts' views. The main goal of the prototype design is to move towards the next phase towards development of a fully function surveillance and control system. In order to design a prototype, this research used InVision prototyping tool along with Adobe XD and protopie. These Prototyping tools are very interesting and interactive for designing prototypes for different computational devices like: laptop, desktop computers, tablets and several kinds of smartphones.

\section{Design Description of a Prototype for Mobile Devices}

The proposed prototype design of a system is composed of a client application running on different kinds of computing devices and a server side prototype application (cloud-based) capable of handling user process or transaction; which is managing the timer set by users and providing the desired social media access and services.
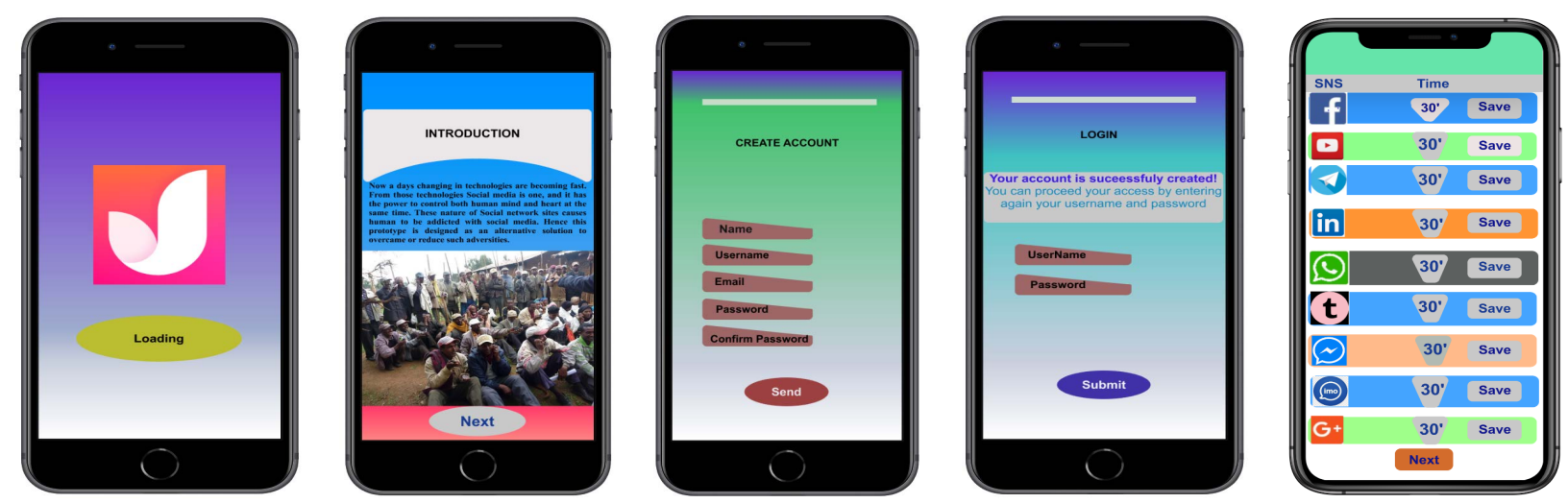


\section{Discussion of the Results}

Nowadays adopting the Cloud Computing technology for assurance of On-demand Scalability, improved Flexibility, Boundary-less Accessibility, Cost-effectiveness, High-end Availability, etc. are the most important features which drive different organizations to migrate their manual or on premise ICT resources, systems and applications over cloud [15]. Because of cloud supported user-friendly, easy and interesting prototyping tools, designers are preferring for designing their prototypes over cloud. In this study, the proposed framework's prototype is also designed using cloud-based InVision studio and Adobe XD. The collected and analyzed facts showed that Ethiopian university communities are utilizing social network sites using mobile, laptop, desktops and tablets for their communications and socializations. Hence this automatic surveillance control prototype for the target users can be directly connected and communicated using internet/cloud to the services developed and delivered over cloud.

\section{Conclusions}

Based upon the primary data collected and analyzed using survey (questionnaire), interview (questionnaire) and observation (checklist), the researcher concluded a clear understanding of the factors and the adversities/disruptions of the social media in the higher learning institutions. For the automated surveillance and control mechanism, the research proposed a cloud-based framework "Automatic Surveillance and Control System Framework along with a functional Prototype" in special reference to Ethiopian higher learning institutions for alleviating the adversities of social media. This cloud-based prototype was designed using prototyping tools: Protopie and InVision studio platforms.

Finally, an Automatic Surveillance and Control System Framework and Prototype design was proposed, designed and checked for acceptance and validation. This Automatic Surveillance and Control System Framework and Prototype provide an anti-addiction vaccination for Close-User Groups (family member or office staff, project members etc.).

\section{Recommendations}

In this study, the system framework prototype is designed and validated over a cloud platform using the free trial version tools and technologies. Therefore, researcher recommended that for the future researchers; if possible, it can be fully implemented over a commercial version of the Prototype design and development tool i.e. the tool which is having fully featured and integrated with all possible computing and communication technology components. This tool can have new and advanced features that are not listed in this study and may be available in future. And also the adverse effects of social media are also expected to study and classify the adverse factors based on the age, relation and educational levels for the future. 


\section{Conflicts of Interest}

The authors declare no conflicts of interest regarding the publication of this paper.

\section{References}

[1] Gebreslassie, Y. and Sharma, D.P. (2019) DPS-Yemane-Shareme CSMM Model for Client-Side SLA of Green Cloud Services Measuring and Monitoring. IUP Journal of Computer Sciences, 13, 34-46.

[2] Sharma, D.P. and Tuni Gure, A. (2019) Assessment of Knowledge Sharing Practices in Higher Learning Institutions: A New Exploratory Framework-AT-DP KSPF. IUP Journal of Knowledge Management, 27, 1-15.

[3] Sharma, D.P. and Bhatia, D. (2014) A Comparative Analysis of Proactive, Reactive and Hybrid Routing Protocols over open Source Network Simulator in Mobile Ad Hoc Network. International Journal of Applied Engineering Research, 11, 3885-3896.

[4] Gautam, S.K. and Sharma, D.P. (2014) Distributed \& Prioritized Scheduling to Implement Carrier Aggregation in LTE Advanced System. 2014 Fourth International Conference on Advanced Computing \& Communication Technologies of IEEE, Rohtak, 8-9 February 2014.

[5] Oaks, T. (2016) Social Media, Definition and Classes of. In: Harvey, K., Ed., Encyclopedia of Social Media and Politics, Elsevier, Amsterdam, 1158-1162.

[6] Kumlachew, S.S. (2014) Challenges and Opportunities of Facebook as a Media Platform in Ethiopia. Journal of Media and Communication Studies, 16, 99-110.

[7] Pantic, I. (2015) Online Social Networking and Mental Health. Cyberpsychology, Behavior and Social Networking, 17, 652-657.

https://doi.org/10.1089/cyber.2014.0070

[8] Pendergrass, W.S. (2015) A Case Study Analysis of Evolving Issues Related to Social Media Use and Abuse through Smartphones.

[9] Igor, P.V. (2014) Cyber Phychology, Behaviour and Social Networking (Online Social Networking and Mental Health).

[10] Sharma, R.K. and Durga Prasad Sharma, A.A.J. (2009) Convergence of Intranetware in Project Management for Effective Enterprise Management. Journal of Global Information Technology, 4, 65-85.

[11] Badmos, K. (2014) Effect of Social Media on the Church. 2014 Annual Conference of Theological Friends and Fellows, the Redeemed Christian Bible College Lagos, Nigeria, 4-6.

[12] Alimurat Kirink, A.A. (2015) A Quantitative Research on the Level of Social Media Addiction among Young People in Turkey.

[13] Sharma, D.P. and Khandelwal, K.K. (2013) Hybrid Reasoning Model for Strengthening the Problem Solving Capability of Expert Systems. International Journal of Advanced Computer Science, 4, 88-94. https://doi.org/10.14569/IJACSA.2013.041014

[14] Dissertation, P.L. (2019) Purposive Sampling. http://dissertation.laerd.com/purposive-sampling.php\#maximum-variation-sampling

[15] Samuel (2019) Designing a Cloud Based Unique ID System Framework for Ethiopian Citizens. 